\title{
Peran Madrasah Dalam Inplementasi Ilmu-Ilmu Islam
}

\author{
Muhammad Yusuf ${ }^{1}$, Andi Ombong Sapada ${ }^{2}$ Agus Basri $^{3}$, Ali Akbar ${ }^{4}$
}

\begin{abstract}
${ }^{1}$ Sekolah Tinggi Agama Islam (STAI) Darul Dakwah Wal-Irsyad (DDI) Kota Makassar, Indonesia Email: yusufburhan8588@gmail.com

${ }^{2}$ Sekolah Tinggi Agama Islam (STAI) Darul Dakwah Wal-Irsyad (DDI) Kota Makassar, Indonesia Email: andiosapada@gmail.com

${ }^{3}$ Sekolah Tinggi Agama Islam (STAI) Darul Dakwah Wal-Irsyad (DDI) Kota Makassar, Indonesia Email: agusbasritakko@gmail.com

${ }^{4}$ Sekolah Tinggi Agama Islam (STAI) Darul Dakwah Wal-Irsyad (DDI) Kota Makassar, Indonesia Email: ali.aakbar05@gmail.com
\end{abstract}

\begin{abstract}
Abstrak:
Madrasah dalam era modern berada dalam kondisi tarik menarik antara keharusan mempertahankan ilmu-ilmu agama secara modern di satu pihak, dan mengembangkan pengajaran ilmu-ilmu non keagamaan di lain pihak. Sikap madrasah yang terlalu konservatif, akan menyebabkan lembaga ini terasing dan bahkan lenyap dari perkembangan modern. Sebaliknya, sikap akomodatif yang berlebihan terhadap kecenderungan pendidikan modern, akan menjerumuskan madrasah ke dalam sistem pendidikan yang lepas dari nilai-nilai keislaman.
\end{abstract}

Kata Kunci: Madrasah, Impementasi, Ilmu-Ilmu Islam

\section{PENDAhUluan}

Madrasah sebagai sekolah yang berciri khas Islam di Indonesia, sudah menjadi bagian dari keseluruhan sistem pendidikan nasional. Pandangan ilmiah membenarkan kenyataan bahwa madrasah merupakan bagian dari tradisi pendidikan yang hidup di Indonesia. ${ }^{1}$

Dari segi keilmuan, ilmu-ilmu yang diajarkan di madrasah hanyalah ilmuilmu keagamaan, seperti fikih, tafsir, hadis, dan tauhid. Sedangkan ilmu-ilmu eksakta sebagai dasar pengembangan sains dan teknologi tidak mendapat tempat, karena posisi madrasah menaruh jarak dengan sains modern. Itulah sebabnya sehingga madrasah sering disebut sebagai lembaga pendidikan tradisional. ${ }^{2}$

Kekhawatiran itu lebih mencekam lagi ketika keluar Kepres No. 34 tahun 1972 tentang Tanggung Jawab Fungsional Pendidikan dan Latihan. Dua tahun

16.

${ }^{1}$ A. Malik Fadjar, Madrasah dan Tantangan Modernitas (Cet. II; Bandung: Mizan, 1999), h.

${ }^{2}$ Syafi'i Ma'arif mengatakan bahwa madrasah lebih menonjolkan kemenangan di akhirat dan mengalah atas kepentingan dunia. Lihat Muslih Usa dan Aden Wijdan SZ, Pendidikan Islam dalam Peradaban Industrial (Cet. I; Yogyakarta: Aditya Media, 1997), h. 83. 
berikutnya, Kepres itu dipertegas dengan Inpres No. 15 tahun 1974 yang mengatur tentang realisasinya. Dengan adanya Kepres dan Inpres tersebut, maka umat Islam memberi reaksi, terutama pengelola lembaga pendidikan Islam. Akibatnya, keluarlah SKB 3 Menteri pada tahun 1975 tentang Peningkatan Mutu Madrasah, yang secara nasional dapat dikatakan menjadi tonggak penting integrasi pendidikan nasional. $^{3}$

\section{PEMBAHASAN}

\section{A. Pengertian Madrasah}

Menurut Maksum, madrasah adalah salah satu jenis lembaga pendidikan Islam yang berkembang di Indonesia yang diusahakan di samping masjid dan pesantren. Pencetus pertamanya adalah tokoh Syekh Zaenuddin Labai yang mendirikan lembaga pendidikan madrasah pertama di Padang Panjang pada tanggal 10 Oktober $1915 .{ }^{4}$

Di lain pihak, Mappanganro berpendapat bahwa madrasah pertama lahir di Padang dengan nama sekolah Adabiyah (Adabiyah School), yang didirikan oleh Almarhum Syekh Abdullah Ahmad pada tahun 1909. ${ }^{5}$

Secara etimologis, kata madrasah berasal dari bahasa Arab, yakni dari kata y yang berarti “belajar". Sehingga secara terminologis dapat dikatakan bahwa madrasah berarti tempat belajar. ${ }^{6}$

Pemakaian kata madrasah sekarang ini di Indonesia, menunjuk kepada suatu bentuk lembaga pendidikan Islam, seperti Madrasah Ibtidaiyah yang sederajat dengan Sekolah Dasar (SD), Madrasah Tsanawiyah yang sederajat dengan Sekolah

${ }^{3}$ Marwan Saridjo, Bunga Rampai Pendidikan Agama Islam (Jakarta: Amissco, 1996), h. 103.

${ }^{4}$ Maksum, Madrasah Sejarah dan Perkembangannya (Cet. II; Jakarta : Logos Wacana Ilmu, 1999), h. 7.

${ }^{5}$ Mappanganro, Eksistensi Madrasah dalam Sistem Pendidikan Nasional (Ujung Pandang : CV. Berkah Utami, 1996), h. 13.

${ }^{6}$ Mappanganro, Eksistensi Madrasah dalam Sistem Pendidikan Nasional., h. 7. 
Lanjutan Tingkat Pertama (SLTP), Madrasah Aliyah yang sederajat dengan Sekolah Lanjutan Tingkat Atas (SLTA). Lembaga pendidikan Islam tersebut terpadu dengan Sistem Pendidikan Nasional di Indonesia. ${ }^{7}$

\section{B. Implementasi Pendidikan Islam pada Madrasah}

Ada pihak yang berpendapat bahwa dalam era kemajuan teknologi sekarang ini, madrasah tidak memiliki gambaran masa depan yang cerah. Karenanya, para orang tua lebih memilik measukkan anaknya pada sekolah umum daripada di madrasah, sebab sekolah umum lebih memberikan masa depan.

Fenomena di atas dapat ditemui di masyarakat, dengan menurunnya animo masyarakat terhadap madrasah. Akibatnya, banyak madrasah yang mengalami kekurangan peserta didik, hidup enggan, mati pun tidak mau.

Sementara itu, ada juga yang berpendapat bahwa kurangnya animo masyarakat terhadap madrasah, hanyalah kasus lokal. Secara nasional, keberadaan madrasah tetap mempunyai prospek masa depan yang baik.

Dengan tidak menutup mata terhadap gejala yang dikemukakan pihak pertama bahwa bila dibandingkan dengan sepuluh atau dua puluh tahun yang lalu, keadaan madrasah sekarang jauh lebih maju dan berkembang. Grafiknya memperlihatkan peningkatan, terutama jumlah lembaganya. Berdasarkan data yang ada di Departemen Agama, jumlah madrasah yang ada, baik yang negeri maupun swasta, tercatat sekitar 40.000 buah. $^{8}$

Permasalahan yang dihadapi sekarang adalah, ternyata madrasah sangat tidak adaptif dan tidak responsif terhadap peluang pasar. Dalam kaitan ini, Zamakhsyari Dhofier mengatakan bahwa, pendidikan Islam di Indonesia hanya

\footnotetext{
${ }^{7}$ Mappanganro, Eksistensi Madrasah dalam Sistem Pendidikan Nasional., h. 7.

${ }^{8}$ Marwan Saridjo, Bunga Rampai Pendidikan Agama Islam., h. 100.
} 
menempati posisi "kelas dua" dalam masyarakat bangsanya yang mayoritas muslim. ${ }^{9}$

Pihak Departemen Agama, sesuai dengan tugas dan fungsinya, berkewajiban membimbing, membina, dan membandtu pengembangan madrasah, agar sistem dan arah pendidikannya sejalan dan selaras dengan sistem pendidikan nasional.

Pondok pesantren dan madrasah sebagai lembaga pendidikan Islam, telah diakui oleh semua pihak sebagai bagian dari budaya bangsa. Hal itu disebabkan karena lembaga ini telah berjasa mencerdaskan rakyat dan bangsa Indonesia serta berhasil mencetak para pejuang kemerdekaan dan pemimpin bangsa.

Di samping itu, peran madrasah diharapkan dapat mencetak sumber daya manusia yang handal, ahli, dan terampil dalam bidang agama Islam, sehingga mampu mengembang amanat GBHN (Garis-garis Besar Haluan Negara). Maksudnya adalah bahwa pada hakekatnya pembangunan nasional adalah pembangunan manusia Indonesia seutuhnya. ${ }^{10}$

Tenaga ahli dan terampil yang akan melakukan fungsi-fungsi keagamaan di tengah-tengah masyarakat, menjadi kebutuhan umat dewasa ini. Yang dimakduskan dalam hal ini adalah ulama sampai tingkat yang lebih di bawah, seperti guru ngaji, penyuluh agama, pemimpin upacara keagamaan, modin, dan perawatan jenazah. Kesemuanya itu hanya dapat lahir dari madrasah, pondok pesantren, atau perguruan agama Islam.

Melihat kebutuhan dan tuntutan akan tenaga terampil di bidang agama, seperti disebutkan di atas, maka keberadaan madrasah, pondok pesantren, dan perguruan agama Islam yang lain, tetap diperlukan oleh masyarakat Indonesia.

${ }^{9}$ Muslih Usa dan Aden Wijdan SZ, Pendidikan Islam dalam Peradaban Industrial., h. 84.

${ }^{10}$ Marwan Saridjo, Bunga Rampai Pendidikan Agama Islam, h. 100. 


\section{Perkembangan Kurikulum Madrasah}

Sejak awal keberadaannya, madrasah memiliki perbedaan filosofis dengan sekolah umum, yaitu untuk mendidik anak agar mengetahui ajaran agama dan kemudian dapat mengamalkannya dalam kehidupan sehari-hari. ${ }^{11}$ Jadi di zaman serba teknologi sekarang ini, media sosial menjadi salah satu teknologi yang dapat mempengaruhi kehidupan anak. ${ }^{12}$

Kurikulum madrasah, pada hakikatnya tidak terlepas dari konsep awal didirikannya madrasah tersebut, yaitu untuk menghadirkan keseimbangan sikap terhadap ilmu-ilmu umum dan ilmu-ilmu agama. Hal ini berbeda dengan sekolah yang pada umumnya memprioritaskan ilmu umum dan pesantren yang pada umumnya memprioritaskan ilmu-ilmu agama. Selanjutnya telah disebutkan dalam hadist, bahwasanya ilmu yang wajib dicari seorang muslim ada, sedangkan yang lainnya akan menjadi fadhlun (keutamaan). ${ }^{13}$

Hal tersebut sejalan dengan konsep kurikulum pendidikan yang dikemukakan oleh Syekh Naquib al-Attas yang berpendapat bahwa:

Semua ilmu datang dari Allah. Adapun yang membedakannya adalah cara datang dan fakultas indera yang menerimanya. Ilmu berian Allah mengacu pada fakultas dan indera-indera ruhaniah manusia, sementara ilmu capaian mengacu kepada indera jasmaniahnya. Karena 'aql menurutnya sebagai substansi ruhaniah yang menjadikan manusia mampu memahami hakikat dan kebenaran ruhaniah, maka intelek ( ' $a q l$ ) bertindak sebagai penghubung antara yang jasmaniah dan ruhaniah. Demikian juga ilmu berian Allah -yang dideskripsikannya sebagai ilmu agama-itu mutlak penting bagi pembimbingan dan penyelamatan manusia, maka mempelajari ilmu ini hukumnya fardhu 'ain atau wajib bagi semua muslim. Berkaitan dengan kurikulum, maka ilmu-ilmu agama mutlak harus diadakan pada seluruh tingkat pendidikan. ${ }^{14}$

\footnotetext{
${ }^{11}$ Husni Rahim, Arah Baru Pendidikan Islam di Indonesia (Cet. I; Jakarta : Logos Wacana Ilmu, 2001), h. 29.

${ }^{12}$ Sapada, A. O. (2020). Mendidik Anak Menjadi Anak Sholeh., h. 2.

${ }^{13}$ Sapada, A. O., \& Arsyam, M. (2020). Ilmu Pengetahuan dan Teknologi Menurut Pandangan Islam., h. 2.

${ }^{14}$ Maksum, Madrasah Sejarah dan Perkembangannya., h. 50.
} 
Dengan demikian, konsep kurikulum yang menjadi acuan dalam penyusunan kurikulum madrasah adalah konsep keseimbangan dalam memposisikan ilmu pengetahuan umum dengan ilmu pengetahuan agama, sehingga tercapai produk pendidikan yang tidak sekuler dan juga tidak konservatif.

Oleh karena itu, sistem pelaksanaan kurikulum madrasah, harus mempertahankan kekhasannya, dengan merujuk pada konsep pendidikan madrsah itu sendiri, yakni menonjolkan ciri khas keagamaan dalam segala aspeknya, baik aspek materi pelajaran, sarana dan prasarana, format kegiatan belajar, bentuk interaksi di madrasah, dan sebagainya.

Meskipun pada dasarnya, sistem pelaksanaan kurikulum tidak boleh keluar secara total dari sistem pelaksanaan kurikulum madrasah, namun keunikannya sebagai lembaga pendidikan yang berciri khas Islam, harus tetap dipertahankan. Bahkan, untuk memelihara kekhasan madrasah tersebut, pengelolaan madrasah secara teknis tetap berada di bawah naungan Departeman Agama, tidak seperti sekolah umum yang teknisnya dikelola langsung oleh Departemen Pendidikan Nasional.

Adapun sistem pelaksanaan kurikulum madrasah yaitu:

1. Kurikulum pelajaran agama harus lebih banyak dibanding pelajaran agama di sekolah umum. ${ }^{15}$

Proses pendidikan yang berlangsung di madrasah secara umum adalah visualisasi dari konsep pendidikan islami yang selama ini berusaha diterapkan pada sekolah-sekolah agama, termasuk pesantren.

\footnotetext{
${ }^{15}$ Husni Rahim, Arah Baru Pendidikan Islam di Indonesia., h. 134.
} 
Salah satu bentuk atau ciri khas dari sistem pendidikan islami adalah prioritas terhadap pengajaran ilmu-ilmu agama. Ilmu agama adalah ilmu yang mengkaji berbagai seluk beluk agama, ${ }^{16}$ seperti Aqidah Akhlak, Sirah alNabawiyah, Alquran, Hadis, Bahasa Arab, Ulum al-Qur'an, dan sebagainya.

2. Perpaduan antara imtaq (iman dan taqwa) dan iptek (ilmu pengetahuan dan teknologi). ${ }^{17}$

Sebagai bentuk aplikasi dari konsep pendidikan Islam, maka pelaksanaan kurikulum madrasah harus tetap dikonsentrasikan pada upaya mencerdaskan dari segi ilmu pengetahuan dan mereligiuskan siswa dari segi pendidikan agama. Sehingga tercipta pribadi yang mampu bersikap seimbang menghadapi kondisi dua dimensi kehidupan. Hal itulah yang senantiasa ditekankan kepada pengelola madrasah agar pendidikan di madrasah dapat mencapai tujuan yang diharapkan.

3. Penciptaan suasana keagamaan, baik dalam bidang fisik dan sarana, maupun dalam bidang suasana pergaulan dan pakaian. ${ }^{18}$

Salah satu aturan dalam pelaksanaan kurikulum di madrasah adalah senantiasa menampilkan ciri keislaman dalam setiap kegiatan belajar. Hal tersebut meliputi bentuk eksterior dan interior bangunan fisik madrasah, saranasarana belajar yang dipergunakan, juga mengenai aturan berpakaian siswa beserta suasana pergaulannya di lilngkungan madrasah maupun di luar lingkungan madrasah.

\footnotetext{
h. 19.

${ }^{16}$ Juhaya S. Praja, Filsafat dan Metodologi Ilmu dalam Islam (Cet. I; Jakarta: Teraju, 2002),

${ }^{17}$ Juhaya S. Praja, Filsafat dan Metodologi Ilmu dalam Islam, h. 19.

${ }^{18}$ Juhaya S. Praja, Filsafat dan Metodologi Ilmu dalam Islam (Cet. I; Jakarta: Teraju, 2002), h. 19.
} 
Selain kurikulumnya, penjenjangan dan jenis madrasah ditata ulang. Penjenjangan pendidikan madrasah diatur sejalan dengan sistem penjenjangan pendidikan secara nasional. Jenis madrasah di lingkungan Departemen Agama dewasa ini semakin bervariasi, baik yang dikelola oleh pemerintah maupun oleh swasta, mulai dari Madrasah Diniyah Ibtidaiyah sampai ke al-Jami'ah al-Islamiyah, baik negeri maupun swasta.

\section{Dikhotomi Ilmu-ilmu Agama dan Umum}

Dalam berbagai referensi, juga dalam pembicaraan sehari-hari, seringkali istilah pengetahuan agama dan pengetahuan umum menimbulkan masalah. Senada dengan istilah ini, muncul pula istilah sekolah umum dan sekolah agama, guru umum dan guru agama, serta kurkulum umum dan kurikulum agama. Pengkatagorian tersebut lebih cenderung mengarah kepada masalah keduniaan versus masalah keakhiratan, yang tidak mustahil akan terjadi pembagian.

Pada prinsipnya ilmu-ilmu agama bukanlah ilmu-ilmu khusus bagi agama Islam, tetapi hanya ilmu-ilmu yang berdasarkan pandangan Islam. Hal ini menunjukkan bahwa dikhotomi ilmu-ilmu agama dan ilmu-ilmu umum bukan merupakan suatu perbedaan, sebab dalam suatu lembaga pendidikan Islam dipelajari juga ilmu-ilmu umum. Sebaliknya, pada lembaga pendidikan yang bercirikan umum, dipelajari juga ilmu agama.

Ruang lingkup dikhotomi di atas semakin kabur dengan munculnya berbagai paradigma pendidikan dan pengetahuan yang telah berproses. Paradigma baru pendidikan ini berdiri atas suatu konsep: learning to learn, learning to know, learning to live together, and learning to be.

Oleh karena itu pengetahuan akan ilmu agama dan ilmu umum sangat tergantung pada setiap individu Muslim dikehendaki memiliki kesadaran dan pengetahuan dalam menyikapi dan menerima sesuatu yang datang kepadanya, 
berupa penemuan, informasi, maupun pengetahuan. Ikut-ikutan adalah sikap mental yang tidak Qurani, umat Islam harus menjauhinya ${ }^{19}$.

Paradigma baru pendidikan di atas, menuntut masyarakat untuk memiliki suatu kompetensi integral pengetahuan, baik pengetahuan sains, filsafat, maupun pengetahuan mistik. Kesemuanya itu berada pada ruang lingkup pendidikan umum dan pendidikan agama.

\section{KESIMPULAN}

Bertitik tolak pembahasan yang telah dikemukakan sebelumnya, maka berikut ini dapat dikemukakan beberapa kesimpulan, yaitu:

1. Madrasah adalah suatu lembaga pendidikan Islam yang didirikan di samping pesantren. Lembaga pendidikan ini bertujuan untuk mempersempit jurang pemisah antara pendidikan model pesantren yang sifatnya konservatif dengan pendidikan umum yang sifatnya sekuler.

2. Kurikulum madrasah sesuai dengan Undang-undang Pendidikan Nasional, selain mengajarkan ilmu-ilmu agama sebagai ciri khasnya, juga mengajarkan ilmu-ilmu umum. Dengan perpaduan kedua ilmu tersebut, out put-nya diharapkan menjadi manusia yang berkualitas dalam bidang ilmu dan teknologi plus iman dan takwa.

3. Dikhotomi antara ilmu-ilmu agama dengan ilmu-ilmu umum bukanlah suatu perbedaan, sebab ilmu-ilmu umum dipelajari juga di lembaga pendidikan agama, sementara ilmu agama dipelajari pula di lembaga pendidikan umum.

${ }^{19}$ Akbar, A., Basri, A., \& Jamaluddin, H. (2021). Konsep Integrasi Ilmu Agama Dan Ilmu Umum, h. 8 


\section{DAFTAR PUSTAKA}

A. Malik Fadjar, Madrasah dan Tantangan Modernitas (Cet. II; Bandung: Mizan, 1999)

Sapada, A. O. (2020). Mendidik Anak Menjadi Anak Sholeh.

Muslih Usa dan Aden Wijdan SZ, Pendidikan Islam dalam Peradaban Industrial (Cet. I; Yogyakarta: Aditya Media, 1997

Zakirah, Z., Arsyam, M., Altimory, \& Halwa, H. (2020, November 3). Rekonstruksi Wacana Poligami Berbasis Nalar Fiqhi Kontemporer. https://doi.org/10.31219/osf.io/z8epm

Marwan Saridjo, Bunga Rampai Pendidikan Agama Islam (Jakarta: Amissco, 1996)

Arsyam, M., \& Umar, K. (2020). MANUSIA SEBAGAI PENDIDIK PERPEKTIF ISLAM DAN BARAT.

Maksum, Madrasah Sejarah dan Perkembangannya (Cet. II; Jakarta : Logos Wacana Ilmu, 1999)

Arsyam, M. (2020). Guru Seabagai Pilar Pembangunan Bangasa.

Mappanganro, Eksistensi Madrasah dalam Sistem Pendidikan Nasional (Ujung Pandang : CV. Berkah Utami, 1996)

Husni Rahim, Arah Baru Pendidikan Islam di Indonesia (Cet. I; Jakarta : Logos Wacana Ilmu, 2001)

Sapada, A. O., \& Arsyam, M. (2020). Ilmu Pengetahuan dan Teknologi Menurut Pandangan Islam.

Juhaya S. Praja, Filsafat dan Metodologi Ilmu dalam Islam (Cet. I; Jakarta: Teraju, 2002)

Akbar, A., Basri, A., \& Jamaluddin, H. (2021). Konsep Integrasi Ilmu Agama Dan Ilmu Umum

Rifqi, N., Fajrin, M. F., \& Arsyam, M. (2021). Ibadah Sebagai Aspek Ritual Ummat Islam.

Sainuddin, I. H., Arsyam, M., \& Wekke, I. S. (2020). Syekh Yusuf Al-Makassari; Pengembangan Masyarakat Islam.

Usman, H. A., Arsyam, M., \& Yusuf, M. (2021). ETIKA PERDAGANGAN DALAM ISLAM.

Nursalam, N., Basri, A., \& Akbar, A. Implementasi Nikah Dalam Al-Qur'an (Studi Pendekatan Tafsir Maudu'i).

Zakirah, Z. (2020). FIQIH CINTA (Cara Bijak Hukum Islam Menyemai Cinta dan Membina Keluarga). OSF Preprints. September, 28.

Wijayanto, A. (2021). BUNGA RAMPAI Integrasi Keilmuan Dalam Menghadapi New Normal Pada Masa Pandemi Covid-19. 